\title{
USO DE DADOS AEROGEOFÍSICOS DE ALTA DENSIDADE PARA MAPEAMENTO GEOLÓGICO EM TERRENOS ALTAMENTE INTEMPERIZADOS: O ESTUDO DE CASO DA REGIÃO DE CLÁUDIO, PORÇÃO SUL DO CRÁTON SÃO FRANCISCO
}

\author{
Andréia Cristina Ruy ${ }^{1}$, Adalene Moreira Silva ${ }^{2}$, Catarina L. Benfica Toledo ${ }^{3}$ \\ e Carlos Roberto de Souza Filho ${ }^{4}$ \\ Recebido em 14 agosto, 2006 / Aceito em 28 dezembro, 2006 \\ Received on August 14, 2006 / Accepted on December 28, 2006
}

\begin{abstract}
This paper presents an alternative way for mapping in highly weathered terrains using derivative products of high-density airborne geophysical data and their integration with geological data. The new products allowed a better definition of important geological features and supported the geological mapping in 1:100.000 scale. The region of Cláudio, south part of São Francisco Craton is comprised by Archean granite-gneissic terrains (TTG), an amphibolite unit and a supracrustal unit comprised by ultramafic rocks, amphibolites, schists, garnet-sillimanite quartzite and banded iron formation. The integrated approach incorporates the use of Ipatinga São João Del Rey airborne geophysical project and remote sensing data (Landsat-7/ Enhanced Thematic Mapper plus (ETM+)). The derivative products were groundedchecked to examine the efficiency of the magnetic and gamma-ray responses to delineate geological domains. The magnetometric maps provided information to the structural framework and about specific lithological units like mafic and ultramafic bodies, while the gamaespectrometric data brought strong insights about lithological units and boundaries. The data integration, which presents the geophysical and geomorphological characteristics of the lithological groups, shows high potential to better define geological contacts and tectonic structures in highly weathered Archean terrains.
\end{abstract}

Keywords: airborne geophysics, digital image processing; weathered terrains and remote sensing data.

RESUMO. Este artigo apresenta uma alternativa para o mapeamento de regiões fortemente intemperizadas, utilizando produtos extraídos da interpretação de dados aerogeofísicos de alta densidade de amostragem. Os produtos derivados permitiram refinar a feições geológicas importantes e apoiaram o mapeamento geológico na escala 1:100.000. A região de Cláudio, porção sul do Cráton São Francisco, é constituída por terrenos gnáissicos arqueanos (TTG), unidade anfibolítica e unidade supracrustal composta de rochas ultramáficas, anfibolitos, xistos, granada-silimanita quartzitos e formações ferríferas bandadas. 0 trabalho integrado incorpora 0 uso dos dados aerogeofísicos do Projeto Ipatinga São João Del Rey e orbitais multiespectrais (Landsat-7/ Enhanced Thematic Mapper plus (ETM+)). Os produtos gerados foram validados em campo e verificou-se a eficiência da resposta radiométrica e magnetométrica na delimitação dos domínios geológicos. Mapas magnetométricos proveram informações para a caracterização estrutural dos domínios e delimitação de unidades litológicas específicas, tais como corpos máficos e ultramáficos, enquanto mapas gamaespectrométricos foram eficientes no mapeamento de unidades litológicas. A integração dos produtos, os quais mostram simultaneamente assinaturas geofísicas e geomorfológicas de grupos litológicos, mostra alto potencial para definição de contatos geológicos e estruturas tectônicas em terrenos arqueanos muito intemperizados.

Palavras-chave: aerogeofísica, processamento digital de imagem, regiões intemperizadas, sensores remotos.

\footnotetext{
${ }^{1}$ Instituto de Geociências (IG), Universidade Estadual de Campinas (UNICAMP), Caixa Postal 6152, 13083-970 Campinas, SP, Brasil. Telefone: (19) 3521-4696; Fax: (19) 3289-1562 - E-mail: andreiac.ruy@gmail.com

2Laboratório de Geofísica Aplicada, Departamento de Geoquímica e Recursos Minerais, Instituto de Geociências, Universidade de Brasília, 70910-900 Brasília, DF, Brasil. Telefone: (61) 3340-4759 Ramal 25; Fax: (19) 3272-4286 - E-mail: adalene@unb.br

${ }^{3}$ Faculdade de Planaltina, Universidade de Brasília, Campus Planaltina, Área Universitária N.1, 73300-000 Planaltina, G0, Brasil. Tel./Fax: (+55) (61) 3308-5185 -E-mail: cattoledo@terra.com.br

${ }^{4}$ Instituto de Geociências (IG), Universidade Estadual de Campinas (UNICAMP), Caixa Postal 6152, 13083-970 Campinas, SP, Brasil. Telefone: (19) 3788-4535; Fax: (19) 3289-1097 -E-mail: beto@ige.unicamp.br
} 


\section{INTRODUÇÃO}

A região de Cláudio (MG), porção sul do Cráton São Francisco, apresenta algumas limitações naturais que dificultam a aquisição de informações geológicas de campo, as quais incluem um espesso e contínuo perfil de solos desenvolvido sobre o substrato rochoso, provocando uma escassez de afloramentos naturais. No entanto, esta região se destaca no contexto regional, pois uma de suas unidades, composta de rochas ultramáficas, anfibolitos, xistos, granada-silimanita quartzito e BIFs (Banded Iron Formations) é correlacionada ao Supergrupo Rio das Velhas (Oliveira \& Carneiro, 2001). Sua caracterização é extremamente relevante no mapeamento deste e de outros segmentos de mesma natureza na porção sul do Cráton São Francisco.

Este trabalho demonstra que a utilização de dados aerogeofísicos de alta densidade permite uma ampla visualização da distribuição e configuração espacial das unidades litológicas e estruturas tectônicas. A interpretação qualitativa e a integração das imagens gamaespectrométricas e magnetométricas foram efetuadas em ambiente sistema de informações geográficas (SIG), utilizando-se a extensão habitat digitizer do ESRI-ArcView ${ }^{\top \mathrm{M}} 3.2$ resultando na confecção de um mapa geológico da área em escala 1:150.000. 0 trabalho foi complementado pelo uso de modelagem em 2,5 D e integração com dados de sensores remotos no software Envi ${ }^{\mathrm{TM} M}$ 4.2. Os resultados foram validados em trabalho de campo, onde se notou que a expressão de alguns corpos não poderia ser mapeada sem 0 auxílio destes dados, pois os mesmos se encontram na maioria das vezes alterados e as relações de contato nem sempre são claras.

\section{CONTEXTO GEOLÓGICO}

A porção meridional do Cráton São Francisco (Almeida, 1977) é constituída por terrenos granito-gnáissicos arqueanos a paleoproterozóicos, sucessões do tipo greenstone belt arqueanas, rochas metassedimentares paleoproterozóicas e coberturas sedimentares plataformais neoproterozóicas. A região de Cláudio (Figura 1), porção sul do estado de Minas Gerais, pertence a este contexto geológico, sendo constituída por rochas gnáissicas, anfibolíticas e metaultramáficas (metaperidotitos, metapiroxenitos) que foram intrudidas por gabronoritos, granitóides e gabros (Carneiro et al.,1996).

Oliveira \& Carneiro (2001) dividem a região em unidades gnáissica, anfibolítica, supracrustal e máfica fissural (Figura 2). A unidade gnáissica é representada por rochas de composição variando de tonalitos a granitos. A unidade gnáissica de Cláudio exibe composição granodiorítica a diorítica e em algumas regiões granítica.

Estas rochas foram submetidas a eventos magmáticos posteriores, e serviram de substrato siálico para a deposição de seqüências supracrustais geradas desde 0 neoarqueano até 0 neoproterozóico (Fernandes, 2001). As rochas da unidade anfibolítica estão encaixadas nos gnaisses, paralelamente ao bandamento, na forma de diques deformados, que são classificados como hiperstênio anfibolitos. As unidades supracrustais são compostas de rochas ultramáficas, anfibolitos, granadasillimanita-xistos, granada-sillimanita-quartizitos e formações ferríferas bandadas. Elas encontram-se deformadas, metamorfizadas e, localmente, cataclasadas.

A unidade de rochas máficas fissurais é representada pelos diques, de composiçãa ultramáfica e máfica (gabronorito, gabro e diabásio) com trend NW-SE. Esta unidade acompanha a direção das anomalias magnéticas observadas por Oliveira (1999) e Oliveira \& Carneiro (2001). Suas espessuras variam de métricas a decamétricas, cujos comprimentos podem chegar a quilômetros. A zona de cisalhamento de Cláudio possui direção NE-SW e se formou, possivelmente, durante a colagem do Cinturão Mineiro (Teixeira et al., 2000) ao pós-país do orógeno transamazônico (Fernandes, 2001).

\section{NATUREZA DOS DADOS ESTUDADOS}

A área de trabalho é coberta pelos dados do Projeto PitanguiSão João Del Rey-Ipatinga (Figura 1) e faz parte do Programa de Levantamento Aerogeofísico do Governo de Minas Gerais, recobrindo toda a área do Quadrilátero Ferrífero e adjacências. Os métodos empregados neste aerolevantamento foram 0 magnetométrico e o gamaespectrométrico, com altura de vôo fixada em $100 \mathrm{~m}$ sobre 0 terreno e segundo linhas espaçadas de $250 \mathrm{~m}$, e linhas de controle a cada $2.500 \mathrm{~m}$. A área coberta é de $36.385 \mathrm{~km}^{2}$, a qual envolve $160.271 \mathrm{~km}$ lineares, com direções das linhas de produção de N30W e N30E e linhas de controle perpendiculares a estas.

0 levantamento aerogeofísico foi efetuado pela empresa LASA Engenharia e Prospecção S.A., a encargo da SEME (Secretaria de Estado de Minas e Energia do Estado de Minas Gerais), sendo executado utilizando-se dois aviões Cessna 404 - Titan, com velocidade de vôo de $280 \mathrm{~km} / \mathrm{h}$. Na cauda da aeronave, há uma prolongação (stinger), onde é montado 0 aeromagnetômetro, de modo que a influência da aeronave seja minimizada. 0 aeromagnetômetro é constituído por um sensor de vapor de césio com resolução de 0,001nT. 0 sinal é recebido através de um préamplificador, localizado na base do cone da cauda da aeronave, 


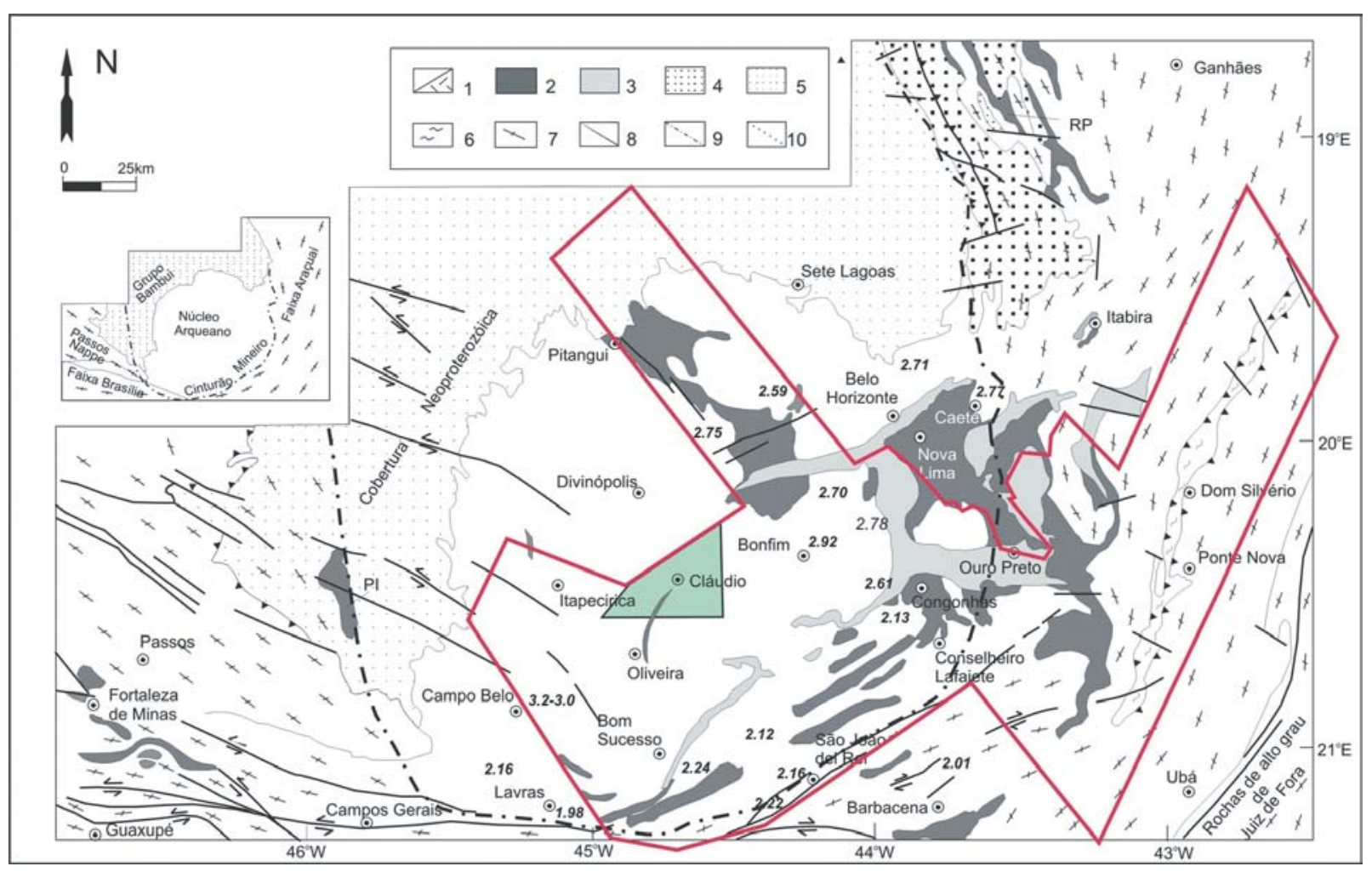

Figura 1 - Mapa Geológico esquemático da Porção Sul do Cráton São Francisco. Notar em verde, a delimitação da área a ser estudada no projeto em apreço (Modificado de Teixeira et al., 2000). 1 - Rochas granitóides-gnaisses-migmatitos e granulitos, parcialmente retrabalhados no Paleoproterozóico (Arqueano); 2 - Greenstone Belts; 3 - Supergrupo Minas (Paleoproterozóico); 4 - Supergrupo Espinhaço (Paleo a Mesoproterozóico); 5 - Grupo Bambuí (Neoproterozóico); 6 - Zona de Cisalhamento/Faixas cisalhadas; 7 - Faixas marginais (Araçuaí, Sul da Faixa Brasília e Nappe de Passos), 8 - Falhas Maiores; 9 - Limite do Cráton; 10 - Foliação Gnáissica. Siglas: PI, RP, FM, CO = Greenstone Belts Piumhi, Rio Paraúna, Fortaleza de Minas e Congonhas; DS - Grupo Dom Silvério (Neoproterozóico). Em detalhe na porção superior esquerda: mapa ilustra os levantamentos executados pela COMIG no estado de Minas Gerais no ano de 2001, com destaque para o recobrimento do Projeto São João Del Rey-Ipatinga, contornada pelo polígono em preto.

e enviado para o sistema de compensação aeromagnética e ao sistema de aquisição de dados. As leituras do magnetômetro são efetuadas a cada décimo de segundo, equivalendo a cerca de 8 metros no terreno.

0 gamaespectrômetro empregado possui 256 canais espectrais, no qual o espectro de cada um dos cristais é analisado individualmente para a determinação precisa dos fotopicos de potássio (40K), urânio (238U) e tório (232Th). As radiações gama detectadas são somadas e as leituras reduzidas a uma única saída de 256 canais espectrais. Realizando-se uma leitura gamaespectrométrica por segundo, obtém-se dados para cada 80 metros do terreno. Demais resultados estão especificados em um relatório final (LASA Engenharia e Prospecção S.A., 2001).

Os dados provenientes de sensores remotos são as cenas do orbital multiespectral Landsat-7/ Enhanced Thematic Mapper plus (ETM+) (órbita WRS 218, ponto 74).

\section{PROCESSAMENTO}

As etapas de processamentos dos dados aerogamaespectométricos e aeromagnetométricos estão sintetizadas nas figuras 3 e 4 . Para os dados gamaespectométricos foram gerados os mapas de K, eTh e eU e contagem total, as composições falsacor RGB e CMY e sua integração com o Modelo Digital de Terreno (MDT). Para os dados magnetométricos, o mapa do campo magnético anômalo a partir do qual gerou-se os seguintes produtos: a amplitude do sinal analítico (ASA) e três derivadas, uma vertical e duas horizontais (Dz, Dx e Dy), bem como o gradiente horizontal total (GHT).

As composições de falsa-cor RGB e CMY também foram integradas com a primeira derivada vertical do campo magnético anômalo (Figura 5). 


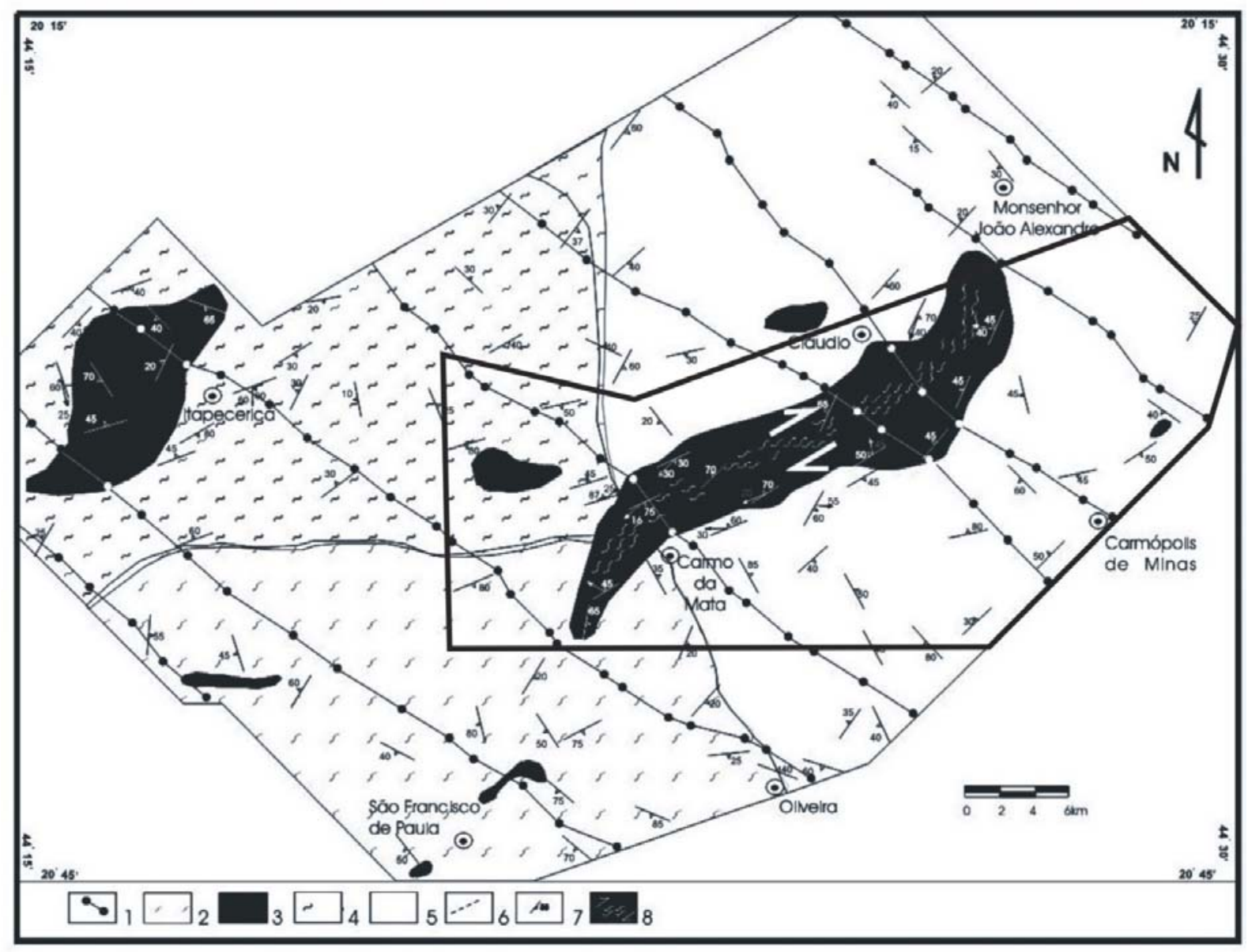

Figura 2 - Mapa prévio para área de estudo, modificado de Oliveira (1999). Unidades: 1 - Máfica fissural; 2 - Supracrustal; 3 - Unidade gnáissica de Candeias; 4 - Unidade gnáissica de Itapecerica; 5 - Unidade gnáissica de Cláudio; 6 - Contatos inferidos; 7 - Foliação; 8 - Zona de Cisalhamento de Cláudio. 0 polígono preto destaca a área enfocada.

A análise do relevo referente ao campo magnético anômalo foi auxiliada por suas transformações lineares, principalmente referentes à amplitude do sinal analítico, demarcando a posição das fontes, fundamental na caracterização dos domínios magnéticos e feições lineares. As derivadas vertical e horizontais do campo magnético anômalo foram úteis na caracterização das posições espaciais relativas destas fontes e na demarcação das zonas de cisalhamento e lineamentos importantes (Luiz \& Silva, 1995).

0 procedimento utilizado na interpretação dos dados gamaespectrométricos envolveu a comparação da imagem correspondente a cada canal discriminado (K, U e Th) com o MDT, visando o estudo da influência do relevo sobre a distribuição destes elementos e a utilização do canal de contagem total na interpretação de grandes domínios gamaespectrométricos (Silva 1999, Silva et al., 2003).
Observou-se ainda a contribuição relativa de cada um dos elementos, utilizando-se composições ternárias em falsa-cor (RGB) com os canais de $\mathrm{K}$, eTh e eU (eventualmente usando o MDT como uma quarta componente), buscando-se, através da análise de sua distribuição espacial, definir unidades e/ou domínios com assinaturas gamaespectrométricas semelhantes. Para os dados de sensores remotos foram aplicadas combinações de bandas e integração com produtos provenientes da geofísica.

\section{REALCE E INTERPRETAÇÃO}

A interpretação qualitativa das imagens foi efetuada em ambiente Sistema de Informaç̧ões Geográficas (SIG). As classificações foram executadas através da extensão habitat digitizer, do software ArcGis ${ }^{\mathrm{TM}} 3.2$ para os dados gamaespectométricos e magnetométricos integrados com o modelo digital de terreno. Esta 


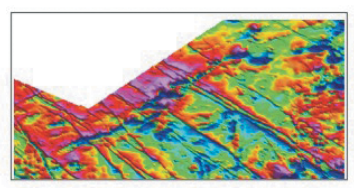

\section{MAGIGRF}

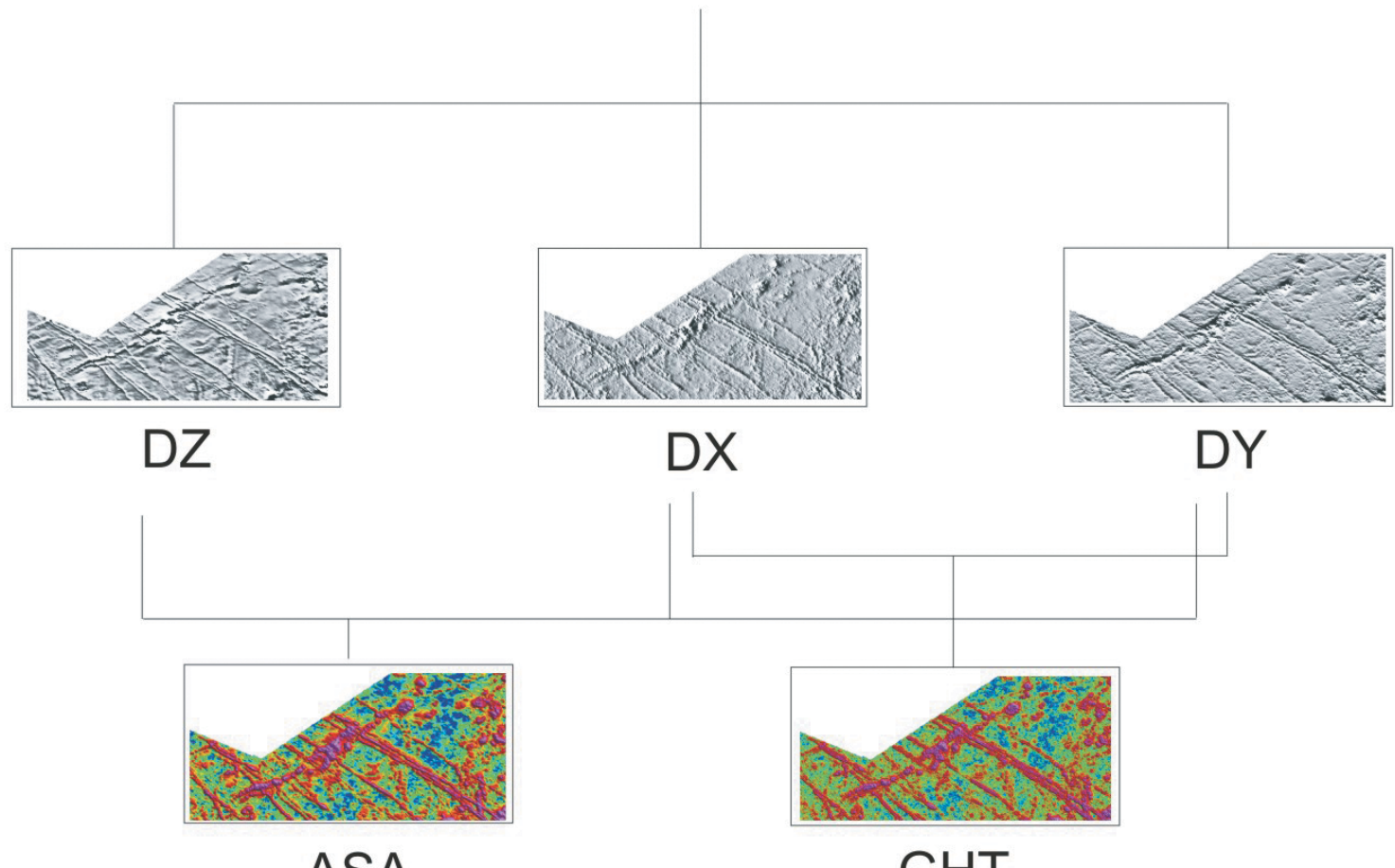

ASA

GHT

Figura 3 - Etapas de processamento dos dados magnetométricos gerados para este projeto. MAGIGRF - campo magnético anômalo; ASA - amplitude do sinal analítico; DZ - primeira derivada vertical do campo magnético anômalo; DX - primeira derivada horizontal em X do campo magnético anômalo; DY - primeira derivada horizontal em Y do campo magnético anômalo, GHT - gradiente horizontal total.

extensão permite classificar hierarquicamente polígonos delineados pela interpretação visual, sendo criada e modificada facilmente, e representa grande vantagem no trabalho de mapeamento geológico.

Com o objetivo de gerar um mapa litogeofísico a partir dos dados gamaespectrométricos, o método empregado foi a classificação qualitativa dos domínios utilizando os canais de $\mathrm{K}$, eU e eTh e as composições falsa-cor RGB e CMY. A extensão foi utilizada para a classificação dos domínios litogeofísicos, através de uma classificação de domínios gamaespectrométricos e seus radioelementos com base na quantidade relativa dos três radionuclídeos utilizados no trabalho (K, eU e eTh). Os teores dos radioelementos foram divididos de acordo com a coloração da imagem falsa-cor RGB, através da localização da cor no triângulo ternário. Cada radioelemento foi classificado em baixo, médio ou alto, resultando em vinte e sete classes distintas para classificação das áreas.

Para a interpretação dos dados magnetométricos utilizou-se, principalmente, a amplitude do sinal analítico, a derivada vertical de primeira ordem e a derivada horizontal de primeira ordem do campo magnético anômalo. No primeiro caso, objetivouse mapear 0 enxame de diques máficos que corta a região, enquanto com o segundo produto buscou-se delinear feições estruturais, não necessariamente relacionadas à intrusão de diques, bem como contatos, descontinuidades ou lineamentos difíceis de serem realçados em mapas de campo magnético anômalo ou outros produtos como sensores remotos. A classificação delimitou os domínios com alta susceptibilidade magnética e a classificação dos polígonos, representando os diques, segundo direções principais em NW-SE e NE-SW. 


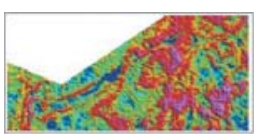

CT

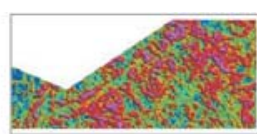

K

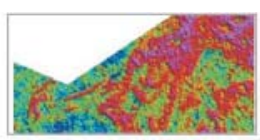

U

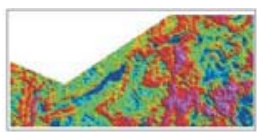

Th

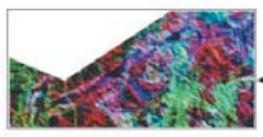

RGB

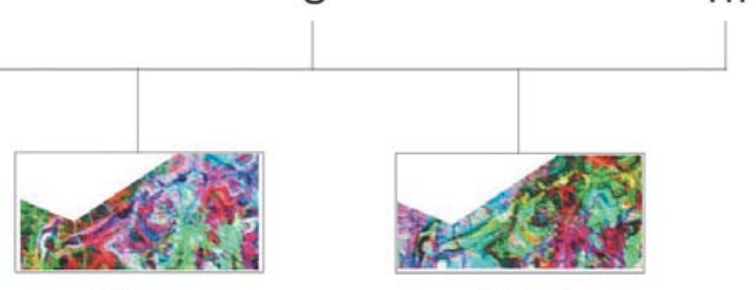

RGB $\quad$ CMY

RGB $\quad$ CMY

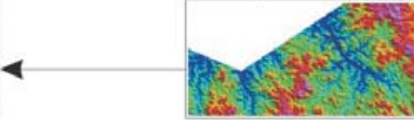

MDT

MDT

CMY

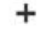

Figura 4 - Etapas de processamento dos dados gamaespectrométricos gerados para este projeto. CT - Contagem Total $(\mu \mathrm{R} / \mathrm{h}), \mathrm{K}$ - Canal de Potássio (\%), U - Canal de Urânio (ppm), Th - Canal de Tório (ppm), RGB - Composição em falsa-cor RGB, colorida com cores aditivas primárias (Red - vermelho, Green - verde, Blue - Azul), CMY Composição em falsa-cor CMY, colorida com cores secundárias (Cian - ciano, Magenta - magenta, Yellow - amarelo). MDT - Modelo digital de terreno.

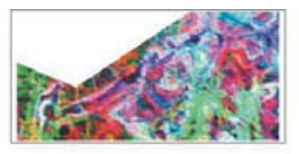

RGB

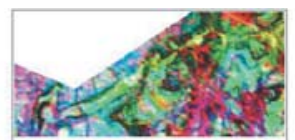

CMY

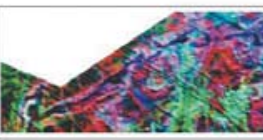

RGB

$+$

DZ

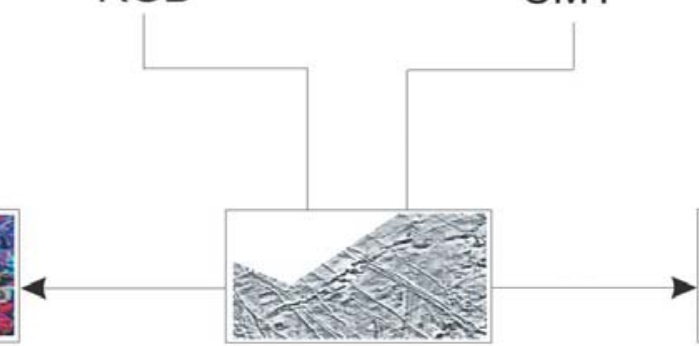

$\mathrm{DZ}$

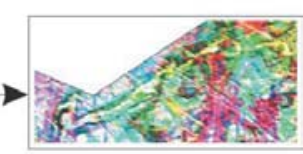

CMY

$+$

DZ

Figura 5 - Etapa de processamento dos dados gerados para este projeto. Integração das composições RGB e CMY com a primeira derivada vertical do campo magnético anômalo. RGB - Composição em falsa-cor RGB, colorida com cores aditivas primárias (Red - vermelho, Green - verde, Blue - Azul), CMY Composição em falsa-cor CMY, colorida com cores secundárias (Cian- ciano, Magenta - magenta, Yellow - amarelo). DZ - primeira derivada vertical do campo magnético anômalo. 


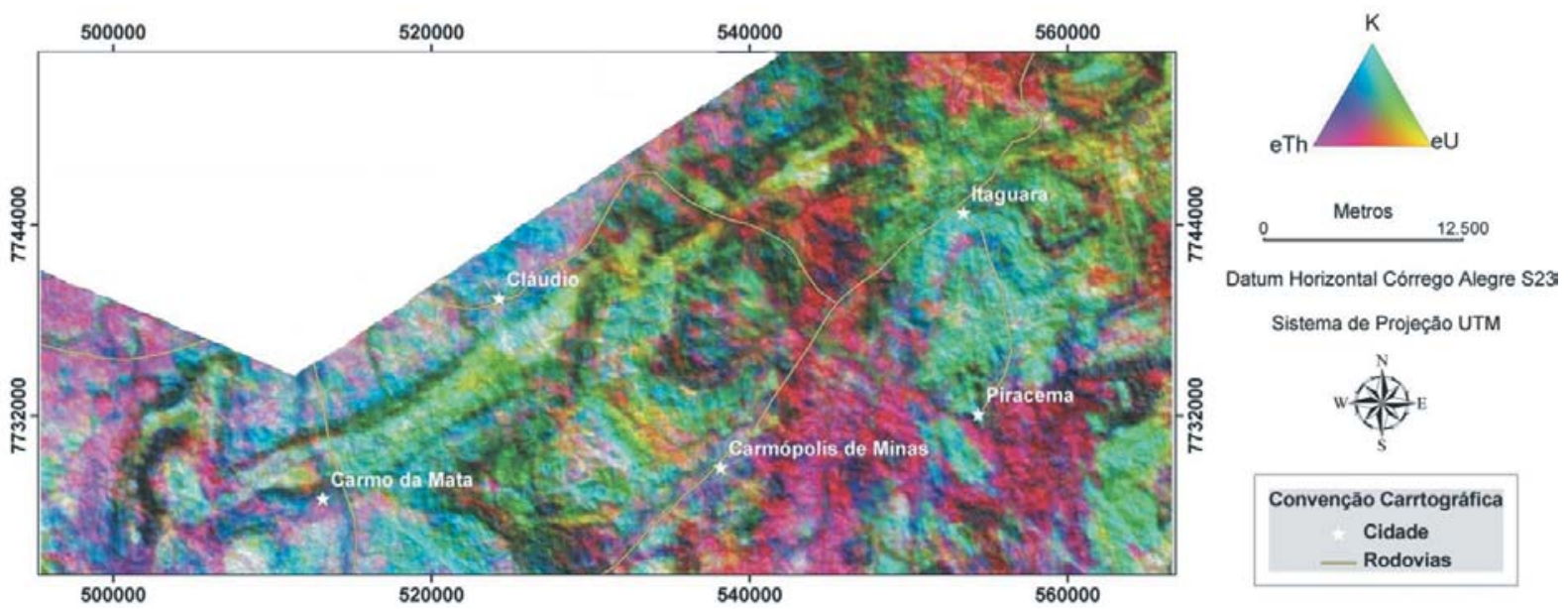

Figura 6 - Sobreposição entre a composição CMY e a banda 8 do Sensor Landsat ETM+. A textura é acentuada pela fusão da banda pancromática com a composição em falsa-cor CMY facilitando a visualização das estruturas.

Os objetivos da integração dos dados multifonte são a visualização da compartimentação geológica da área, com a identificação dos diversos litotipos, e a delimitação de estruturas e lineamentos, agregando os dados do sensor LANDSAT 7 ETM+ aos dados aerogeofísicos de gamaespectrometria e magnetometria. Os melhores resultados da integração entre os dados foram obtidos com 0 uso da banda 8 . 0 uso integrado destas imagens gerou a fusão apresentada na Figura 6, onde as estruturas são marcadas por texturas diferenciadas. 0 uso da geofísica delimita corpos em profundidade, não estando estes necessariamente expostos e sua integração com imagem de sensor mostra a expressão superficial destas anomalias, deste modo a fusão com a banda 8, cuja resolução é de 15 metros, permitiu um detalhamento expressivo na estrutural da área.

\section{RESULTADOS}

0 processamento dos dados gamaespectrométricos e magnetométricos e suas integrações com o modelo digital de terreno resultaram nos seguintes produtos: a) mapa litogeofísico (Figura 7) e b) mapa de feições estruturais e diques máficos (Figura 8). A integração e interpretação dos produtos e sua validação em campo contribuíram para a elaboração de um mapa geológico em escala regional para a área de estudo.

A correlação entre as feições geológicas da área e sua topografia foi obtida através da análise das imagens em 2,5 D geradas com auxilio do programa ENVITM 4.2, uma utilizando a composição ternária RGB e um modelo digital de terreno (MDT) no canal de intensidade e outra contemplando a amplitude do sinal analítico, ambas com exagero vertical de dez vezes
(Figuras 9 e 10).

0 mapa litogeofísico foi interpretado a partir da integração entre a composição ternária RGB (K, eTh, eU) e 0 MDT, auxiliando na caracterização de bordas e contatos entre os domínios. 0 mapa de feições estruturais e diques máficos, confeccionado a partir de dados magnetométricos, possibilitou a delimitação de corpos com alta susceptibilidade magnética. A correlação entre altos na amplitude do sinal analítico, derivados de corpos magnéticos e diques máficos, bem como sua expressão nas imagens gamaespectrométricas, permitiu delinear a expressão em área destes corpos.

Em todas as imagens foi possível destacar a presença da Serra de Cláudio, representada como um grande corpo alongado e localizado na porção central da área de estudo com orientação NESW. Ela é cortada por um enxame de diques, orientados principalmente na direção NW-SE, confirmando observações encontradas na literatura (Silva et al., 1995; Oliveira \& Carneiro, 2001).

Analisando os resultados da imagem em 2,5 D elaborada a partir da composição em falsa-cor RGB (K eTh eU) com o MDT (Figura 9), observa-se a influência do relevo na distribuição destes elementos. A Serra de Cláudio é representado na sua porção central por baixos valores de K, eTh e eU. No entanto, é circundada por altos valores destes elementos. Estes altos valores também representam locais mais elevados na topografia. Estes corpos de coloração branca representam corpos granitóides deformados que circundam a serra. Áreas com altos valores de potássio encontram-se elevadas, possivelmente pela quantidade deste elemento na crosta, sendo a média crustal deste elemento bem elevada em comparação aos outros dois radioelementos. 


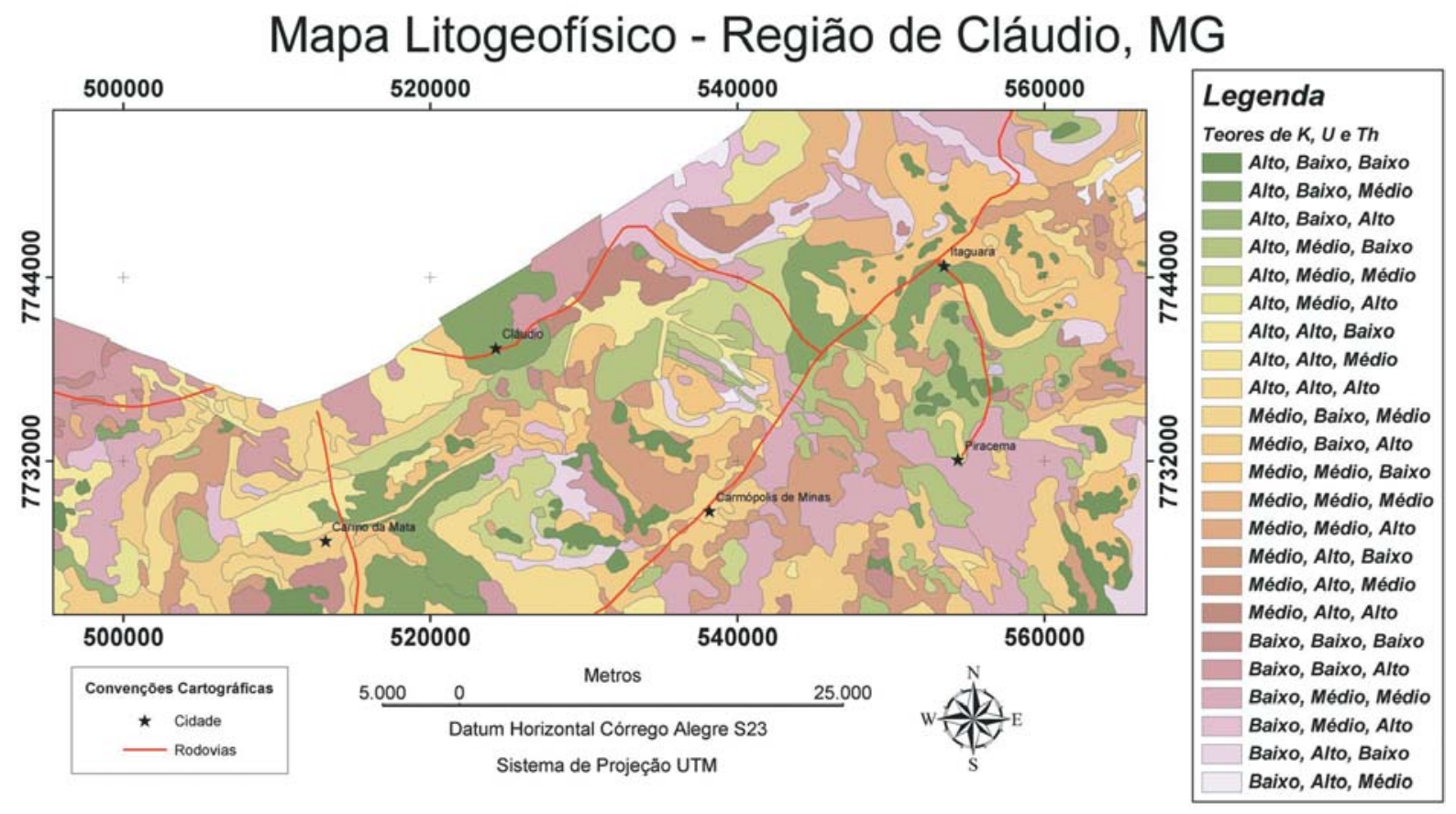

Figura 7 - Mapa litogeofísico para a região de Cláudio, MG.

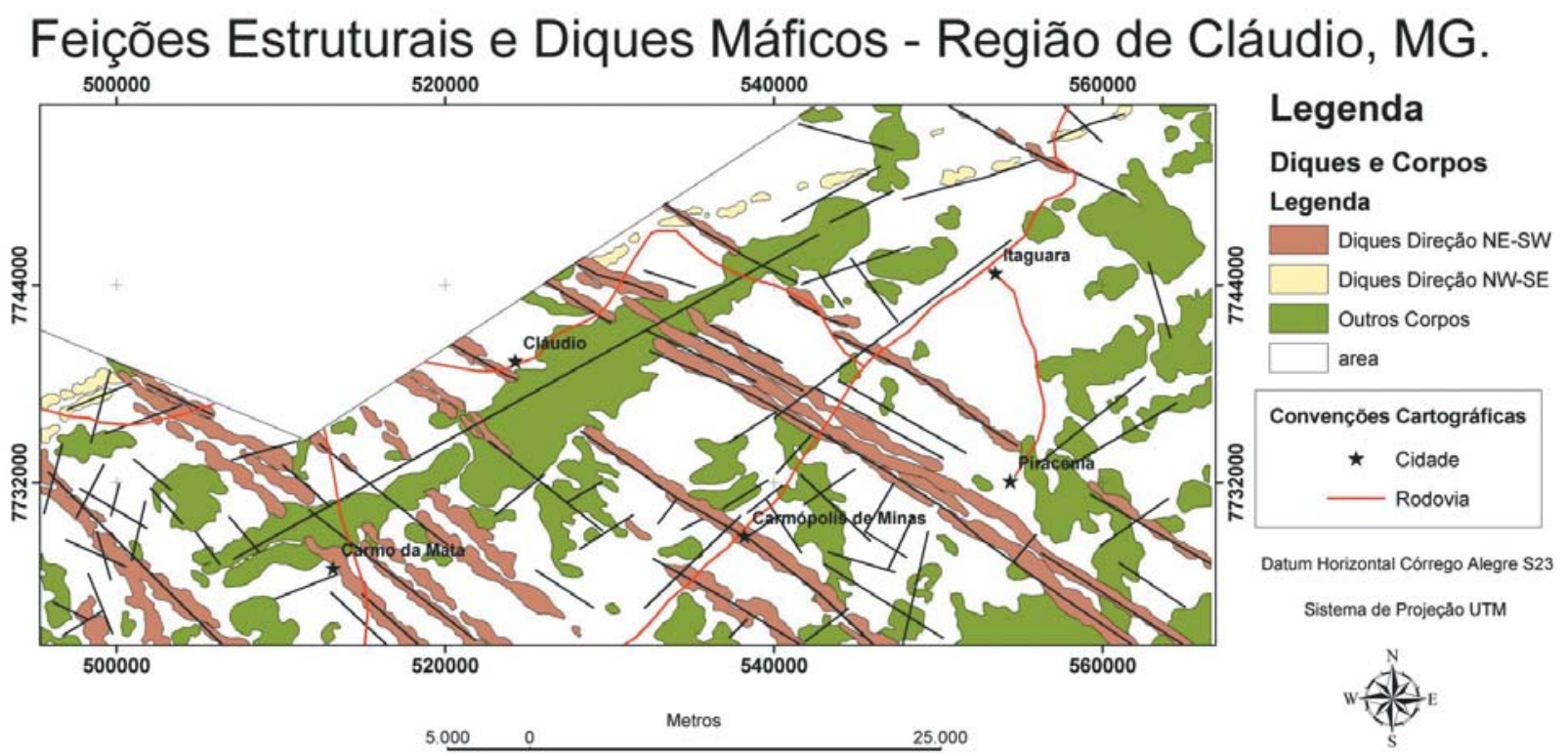

Figura 8 - Mapa de feições estruturais e diques máficos. Região de Cláudio, MG, em escala 1:250000.

Dados da literatura (Ferreira \& Souza, 2002) mencionam os valores $2 \%$ para o K; 2,7 ppm para o U e 8,5 ppm para o Th. Dickson \& Scott (1997) retratam um trend de variação na distribuição dos radioelementos para rochas ígneas, com o aumento de acidez da rocha.
No modelo gerado a partir da amplitude do sinal analítico, a serra mostra altos valores deste parâmetro (Figura 10) e está recortada pelo enxame de diques NW, já mencionado. A maioria dos diques máficos mostra alta amplitude do sinal analítico, alta freqüência espacial nas derivadas e baixos teores nos radio- 


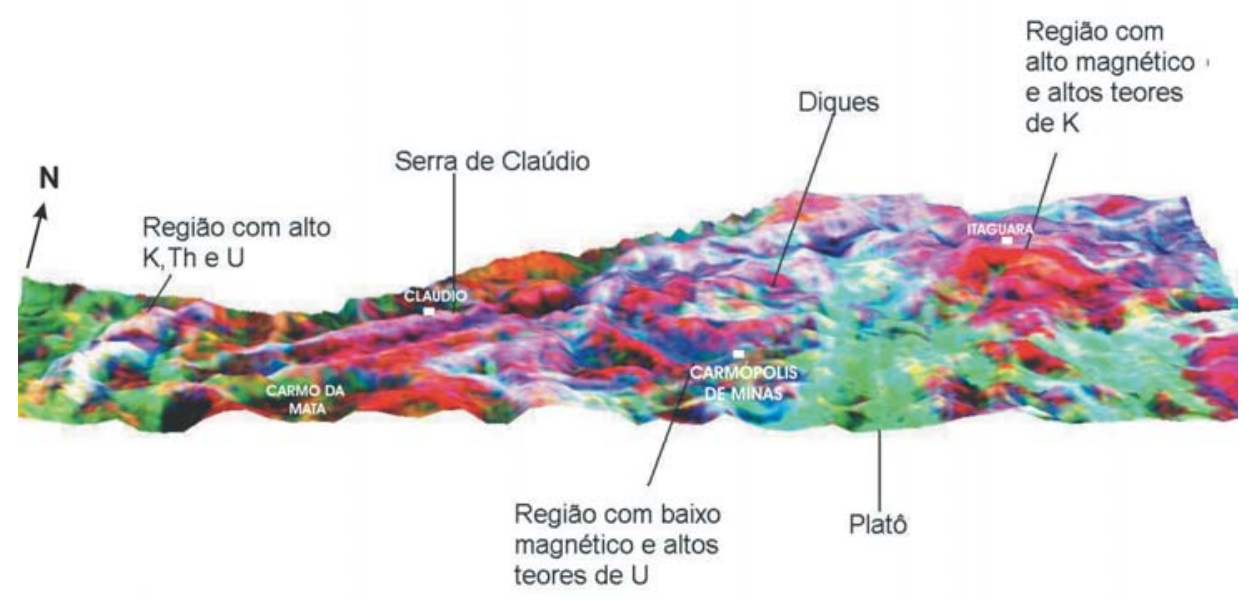

Figura 9 - Modelo em 2,5 D, efetuado a partir de composição ternária falsa-cor RGB (exagero vertical 10 vezes) gerado no software ENVI 4.2. Possível notar altos e baixos gamaespectrométricos, o que reflete a variação dos radioelementos na região de estudo, bem como a sua associação com estruturas importantes (eg. Serra de Cláudio).

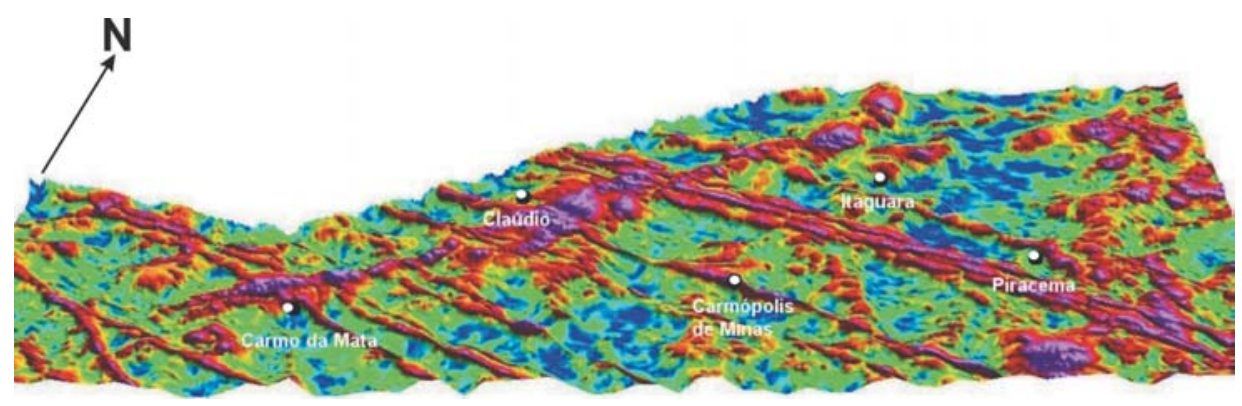

Figura 10 - Modelo em 2,5 D, feito a partir de composição ASA (exagero vertical 10 vezes), gerado no software ENVI 4.0. A imagem ressalta 0 alto gradiente dos diques e corpos máficos e da Serra de Cláudio.

elementos $\mathrm{K}$, eTh e eU. Os diques encontram-se em baixos topográficos em relação ao seu entorno e sua coloração magenta indica provável transporte de $\mathrm{K}$ e eU.

Rochas compostas por teores médios de tório e urânio, representadas pela coloração ciano, e altos de tório encontram-se mais preservadas e, por causa disto, possuem destaque na topografia.

As regiões topograficamente mais baixas estão localizadas sobre as rochas com teores baixos dos três radioelementos, na maioria das rochas máficas e/ou ultramáficas. Em alguns casos, podem indicar uma possível lixiviação destes elementos. No entanto, não há um comprometimento das assinaturas, uma vez que estas rochas são realçadas nos produtos gerados a partir do campo magnético anômalo, pois possuem alta susceptibilidade magnética. Isto reforça que a aplicação deste método é muito eficiente para mapeamento em regiões fortemente intemperizadas.

Com base nos afloramentos visitados, a geologia e a interpretação dos domínios foram correlacionadas validando os as- pectos supra mencionados. Em campo, nos domínios muito intemperizados, não é fácil distinguir a expressão destes corpos de rochas máficas e ultramáficas. Em alguns locais pode-se observar corpos remanescentes em processo de laterização (Figura 11).

\section{DISCUSSÕES E CONCLUSÕES}

A principal contribuição do presente trabalho é 0 auxilio ao mapeamento geológico de regiões intemperizadas, comuns em regiões tropicais, com escassez de exposição de rochas, estruturas e contatos litológicos em superfície.

A comparação entre 0 mapa gerado (Figura 12) neste estudo com aqueles publicados previamente por Oliveira (1999) (Figura 2) mostra grande concordância, especialmente notada nas direções regionais de deformação e nas direções dos diques e corpos da região. 0 mapa litogeofísico, baseado na classificação dos teores de K, eTh e eU, também resultou numa individualização 


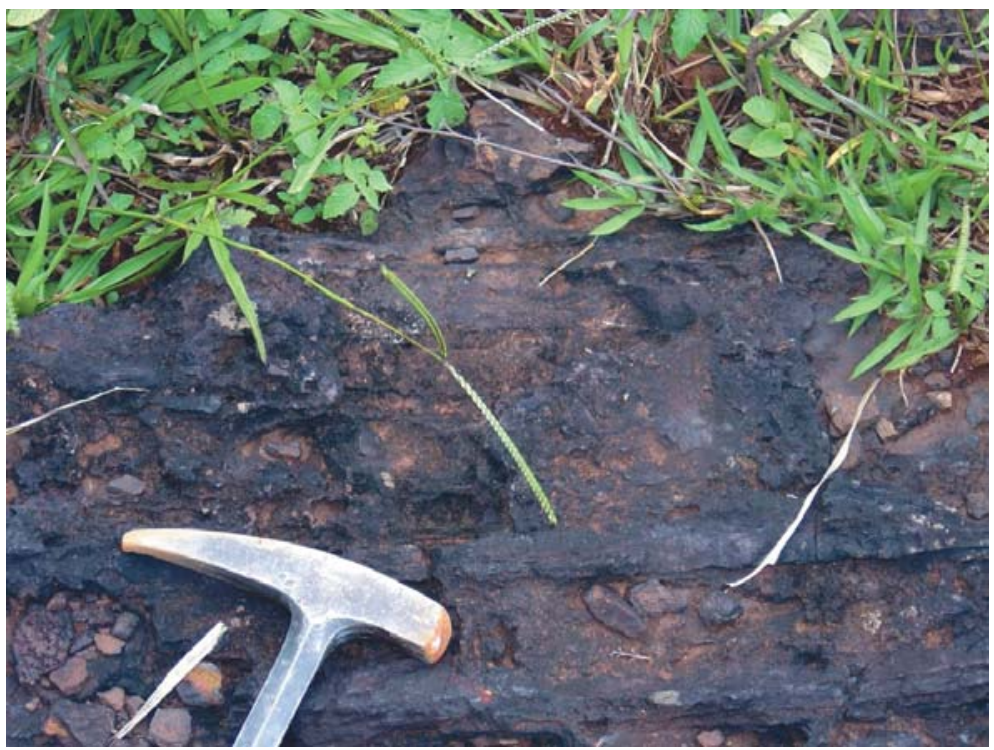

Figura 11 - Afloramento de rocha máfica em processo de laterização.

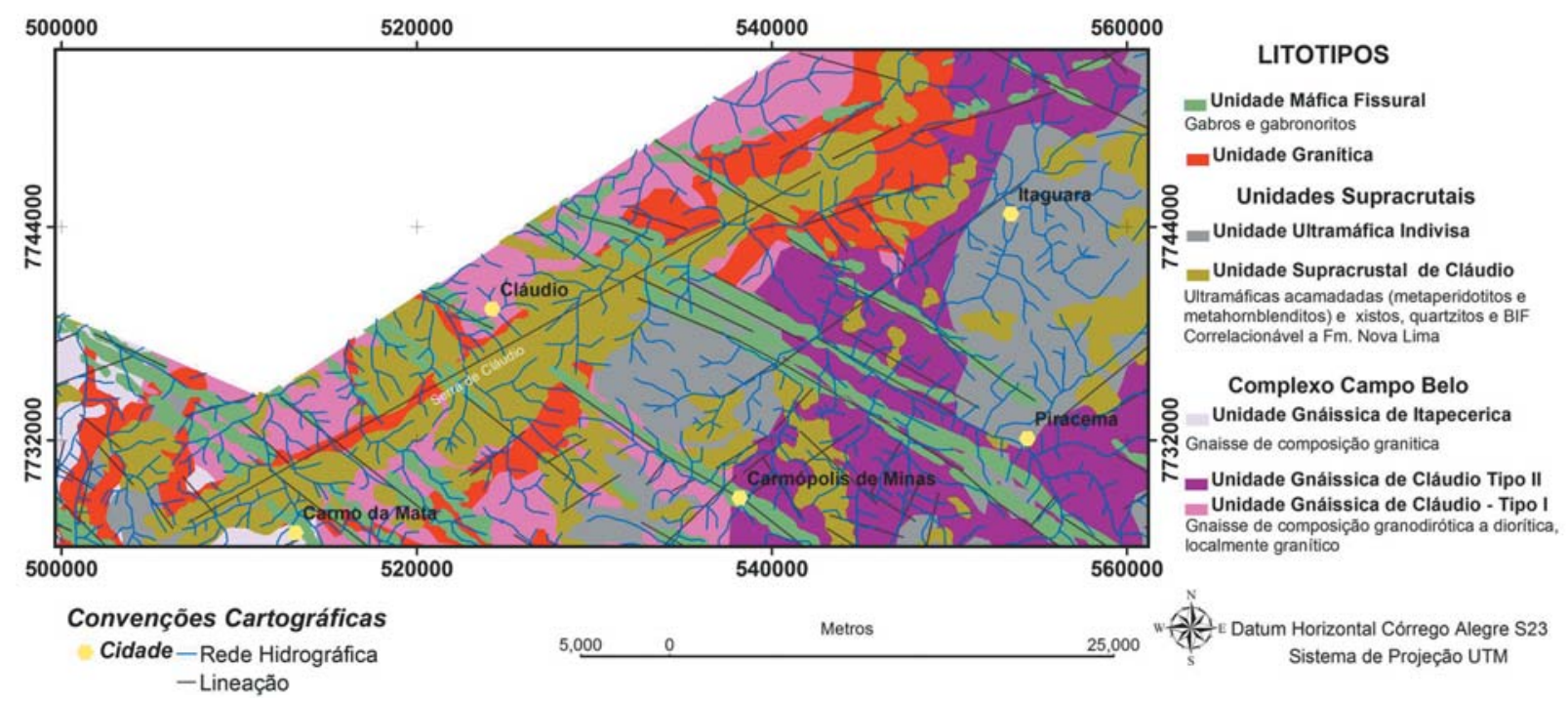

Figura 12 - Mapa Geológico confeccionado em escala 1:100.000 e apresentado em escala 1:250000 Observe que o dado destaca regiões com diferentes amplitudes na Serra de Cláudio, bem como diferencia porções do embasamento granito-gnáissico.

mais depurada da geologia, antes obliterada pela espessa cobertura pedológica da área de estudo. 0 trabalho de campo possibilitou o monitoramento das anomalias geofísicas e correlação com os dados geológicos mapeados nos trabalhos anteriores.

0 mapa geológico (Figura 12) foi concebido através da integração dos mapas litogeofísico e de estruturas, dos trabaIhos de campo e dos produtos do processamento da geofísica e dados de sensoriamento remoto. Com base nas interpretações realizadas distinguiram-se sete unidades: gnáissica de Itapecerica, Cláudio tipo I e Cláudio tipo II (Complexo Campo Belo), ultramáfica indivisa, supracrustal de Cláudio (Unidades supracrustais), granítica e máfica fissural. 0 mapa geológico de Oliveira (1999) (Figura 2) foi consideravelmente refinado. 0 produto final, ou seja, o mapa geológico gerado neste trabalho, segue a nomenclatura adotada pelos autores citados para facilitar a compreensão dos leitores. 


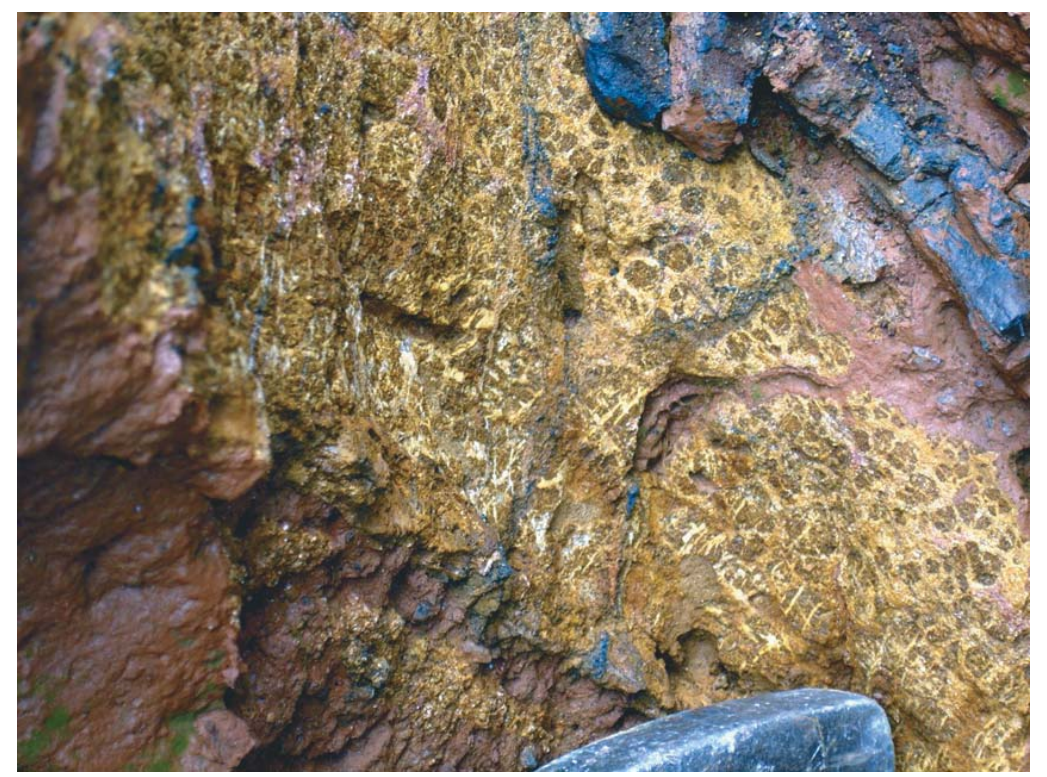

Figura 13 - Forma de ocorrência de rochas ultramáficas na região da Serra de Cláudio. Notar que ainda é possível reconhecer traços da textura original cumulática, apesar do intemperismo intenso.

Delimitou-se três diferentes assinaturas para os gnaisses da região. A unidade gnáissica de Itapecerica, localizada a leste da área e composta por gnaisses de composição granítica, e duas variações para a unidade gnáissica de Cláudio (Tipos I e II). A unidade gnáissica de Cláudio, representativa do embasamento, é composta por gnaisses de composição granodiorítica a diorítica e domina a maior porção da área.

Sobre os gnaisses afloram corpos da unidade supracrustal composta por corpos máficos e ultramáficos, entre eles anfibolitos, BIFs e xistos máficos. Esta unidade é correlacionada por Oliveira (1999) com a Formação Nova Lima, do Supergrupo Rio das Velhas. 0 mesmo autor denomina os corpos correspondentes a Serra de Cláudio como Unidade Supracrustal de Cláudio. Os produtos gerados foram especialmente importantes para a delimitação desta unidade, cuja expressão em superfície é muitas vezes obliterada pelo intemperismo. 0 exemplo apresentado na Figura 13 ilustra a forma de ocorrência desta unidade, na qual rochas máficas e ultramáficas cumuláticas muito alteradas ainda preservam a textura ígnea original.

A unidade granítica localiza-se no entorno da Serra de Cláudio é composta por corpos graníticos com anomalia expressiva na gamaespectrometria. Diques de composição gabróica e gabronoritos cortam as litologias supracitadas. Eles apresentam duas orientações NW-SE e NE-SW, sendo a última mais marcante na região. Esta unidade foi correlacionada a Unidade Máfica Fissural, definida por Oliveira (1999).
Os métodos de pré-processamento, processamento e realce aplicados aos dados magnetométricos e gamaespectrométricos abordados nesta pesquisa, foram bastante efetivos no sentido de gerar produtos para a interpretação geológica. Dentre estes, a amplitude do sinal analítico, a composição ternária RGB (K, eTh e eU) e 0 canal de tório foram críticos para a caracterização de domínios e estruturas geológicas na área de estudo, muitas das quais estavam ausentes nos mapas geológicos previamente produzidos por Oliveira (1999). É importante ressaltar, que não existe uma cartografia sistemática nesta região, apenas os dados gerados pelo autor supracitado. 0 produto final gerado nesta pesquisa foi um mapa geológico que possui um maior detalhe que 0 anterior, ressaltando a importância em se utilizar dados aerogeofísicos em regiões altamente intemperizadas.

\section{AGRADECIMENTOS}

Agradecemos à Companhia de Desenvolvimento Econômico de Minas Gerais (CODEMIG) e a Secretaria de Minas e Energia (SEME) do Governo de Minas Gerais pela liberação dos dados do Levantamento Aerogeofísico do Projeto Pitangui-São João Del Rey-Ipatinga utilizados nesta pesquisa e à FAPESP pelo projeto de Auxílio à Pesquisa (Proc. N. 2002/09038-6). A primeira autora, Andréia Cristina Ruy, agradece ao programa SAE/UNICAMP e ao PIBIC/CNPq pela concessão das bolsas de iniciação científica (2004 e 2005). 


\section{REFERÊNCIAS}

ALMEIDA FFM de. 1977. O Cráton São Francisco. Rev. Bras. Geociências, 7(4): 349-364.

CARNEIRO MA, TEIXEIRA W, NALINI JR A, OLIVEIRA AH de \& CARVALHO JR IM. 1996. Archean ultramafic-mafic magmatism in the southern São Francisco Craton (Campo Belo Complex) : Preliminary petrographic and geochemical results. In: Anais do Simpósio de Terrenos Arqueanos da Plataforma Sul-Americana, p. 32-33.

DICKSON BL \& SCOTT KM. 1997. Interpretation of aerial gamma-ray surveys - adding the geochemical factors. AGSO Journal 17(2): 187200.

FERNANDES RA. 2001. Etapas de Formação de Crosta Continental (de Mesoarqueano ao Mesoproterozóico) no Cráton São Francisco Meridional. DEGEO. Univ. Federal de Ouro Preto. Dissertação de Mestrado. $120 \mathrm{p}$.

FERREIRA FJF \& SOUZA JL. 2002. Gamaespectrometria - Fundamentos, Geoquímica e Distribuição dos Radioelementos em Rochas e Solos. LPGA, Dep. Geologia UFPR. Curitiba, $72 \mathrm{p}$.

LASA ENGENHARIA E PROSPECÇÕES S.A. 2001. Relatório Final do Levantamento e Processamento dos Dados Magnetométricos e Gamaespectrométricos. Levantamento Aerogeofísico de Minas Gerais, Área 2. Projeto Pitangui-São João Del Rey-Ipatinga. Volume I, Texto técnico.

LUIZ JG \& SILVA LMC. 1995. Geofísica de Prospecção. Belém, UFPA, Cejup, $311 \mathrm{p}$.
OLIVEIRA AH \& CARNEIRO MA. 2001. Campo Belo Metamorphic Complex: Tectonic Evolution of an Archean sialic crust of the southern São Francisco Craton in Minas Gerais (Brazil). Anais da Academia Brasileira de Ciências, 73(3): 397-415.

OLIVEIRA AH. 1999. Evolução Tectônica de um Segmento Crustal Arqueano do Cráton São Francisco Meridional. DEGEO. Univ. Federal de Ouro Preto Dissertação de Mestrado. 104 p.

SILVA AM. 1999. Integração de dados geológicos e geofísicos utilizando-se uma nova técnica estatística para seleção de alvos para exploração mineral, aplicada ao Greenstone Belt Rio das Velhas, Quadrilátero Ferrífero. Univ. Brasília. Tese de Doutorado.

SILVA AM, CHEMALE JR F, KUMUYUMJIAN RM \& HEAMAN L. 1995. Mafic Dike Swarms of Quadrilátero Ferrífero and Southern Espinhaço, Minas Gerais, Brazil. Rev. Bras. de Geociências, 25(2): 124-137.

SILVA AM, PIRES ACB, McCAFFERTY AE, MORAES RAV \& XIA H. 2003. Application of airborne geophysical data to mineral exploration studies in the uneven exposed terrains of the Rio das Velhas Greenstone Belt. Rev. Bras. Geociências, 33: 17-28.

TEIXEIRA W, SABATÉ P, BARBOSA J, NOCE CM \& CARNEIRO CA. 2000. Archean and Paleoproterozoic Evolution of the São Francisco Craton, Brazil. In: CORDANI UG, MILANI EJ, THOMAZ FILHO A \& CAMPOS A. (Ed.). Tectonic Evolution of South America, p. 101-137.

\section{NOTAS SOBRE OS AUTORES}

Andréia Cristina Ruy. Geóloga (2006) graduada pela Universidade Estadual de Campinas. Faz parte do grupo de Geotecnologias da Unicamp e atua na linha de pesquisa de Geotecnologias aplicadas ao estudo dos recursos naturais. Bolsista CNPq de Iniciação Científica (2003-2006), implementando técnicas de processamento e integração de dados multi-fontes (aerogeofísicos e de sensores remotos).

Adalene Moreira Silva. Engenheira Geóloga (1989) graduada pela Universidade Federal de Ouro Preto, Mestre (1992) e Doutora em Geologia (1999) pela Universidade de Brasília. Profissionalmente foi pesquisadora do Serviço Geológico Americano (1997-1999), Professora Visitante da Universidade de Brasília (2000-2002), Pesquisadora (05/2002-04/2003) e Professora do Instituto de Geociências da UNICAMP (04/2003-10/2005). Atualmente é Professora do Instituto de Geociências da UnB. Professora Adalene vem ensinando e pesquisando sobre novas técnicas de processamento, interpretação e integração de dados aplicados a exploração mineral, hidrogeologia e ambiente.

Catarina Labouré Benfica Toledo. Geóloga graduada pela Universidade Federal do Rio de Janeiro (1991), Mestre em Metalogênese (1997) e Doutora em Geociências (2002) pela Universidade Estadual de Campinas. Pesquisadora da Universidade Estadual de São Paulo (2006). Nos últimos dez anos tem trabalhado na borda meridional do Cráton do São Francisco com cartografia geológica, estrutural e evolução crustal. Atualmente, é professora do Curso de Ciências Naturais da UNB e tem se dedicado ao estudo de evolução crustal em terrenos Pré-cambrianos, com base na integração de dados geológicos, isotópicos e aerogeofísicos (auxílios Fapesp e CNPq).

Carlos Roberto de Souza Filho. Engenheiro Geólogo (Universidade Federal de Ouro Preto, 1988), Mestre em Metalogênese (UNICAMP, 1991), PhD (Open University, Inglaterra, 1995, Jovem-Pesquisador (FAPESP-UNICAMP, 1995-1997), Professor-Doutor (UNICAMP, 1997-2002). Desde 2002, é Professor Livre Docente do Departamento de Geologia e Recursos Naturais do Instituto de Geociências da UNICAMP. Atualmente é Coordenador do Programa de Pós-graduação de Geociências e líder do Grupo de Geotecnologias do IG. Pesquisador Nível 1 do CNPq, é responsável pelos laboratórios de pesquisa em Fs-LA-ICP-MS (IsoGeo), Espectroscopia de Reflectância (LER) e Processamento de Informações Georreferenciadas (LAPIG). É pesquisador da NASA nos programas ASTER e Mars-Earth Analogs, Editor-Associado das Revistas Computers \& Geosciences e Mathematical Geology. 